\title{
Do some anxiety disorders belong to the prodrome of bipolar disorder? A clinical study combining retrospective and prospective methods to analyse the relationship between anxiety disorder and bipolar disorder from the perspective of biorhythms
}

Na Du ${ }^{1,2}$, Ya-ling Zhou'2, Xu Zhang ${ }^{2}$, Jing Guo ${ }^{2}$ and Xue-li Sun ${ }^{2 *}$

\begin{abstract}
Background: In clinical practice, some patients diagnosed with anxiety disorder (AD) may develop bipolar disorder (BD) many years later, and some cases of AD may be cured by the use of mood stabilizers. However, the relationship between $A D$ and $B D$ should be explored further.

Method: To track how many cases of $A D$ turned to $B D$ and to discover the differences between them, we recruited 48 patients diagnosed with $\mathrm{BD}$, who were assigned to the $\mathrm{BD}$ group for the retrospective analysis, and we also recruited 186 patients diagnosed with $\mathrm{AD}$ at enrolment; this latter group was asked to complete follow-up surveys conducted 3 months, 6 months, 12 months and 18 months after the primary stage of the study. We defined another two groups according to the usage of mood stabilizers, the rates of reduction in scores on the Hamilton Anxiety Scale and Yale-Brown Obsessive Compulsive Scale, and the changes in Clinical Global Impression scores at different followup times: the anxiety group and the atypical BD group (who used mood stabilizers to treat AD). All subjects also completed the NEO Five-Factor Inventory and supplied blood samples to be tested for several endocrine indices (TSH, T3, FT3, T4, FT4, ACTH,PTC) and inflammatory cytokines (IL-6, IL-8, IL-10, TNF-a, CRP) at enrolment.

Results: In total, 14 subjects developed BD by the end of the study. One hundred eleven subjects were included in the anxiety group. Sixty-three subjects were assigned to the atypical BD group, and they had similar features to the 48 subjects in the BD group in terms of personality traits, abnormality rates of endocrine indices and levels of inflammatory cytokines. From the anxiety group to the atypical BD group and then the BD group, the age of first onset gradually decreased, while the frequency of onset and the score of suicidal ideation gradually increased. Furthermore, the atypical BD group showed markedly higher levels of TSH, IL-6, TNF- $a$ and CRP than the other two groups.
\end{abstract}

Conclusions: Some ADs with unique features might belong to the prodromal stage or the atypical presentation of BD, and recognizing these ADs early will economize many medical resources.

Keywords: Bipolar disorder, Anxiety disorders, Biorhythm

\footnotetext{
* Correspondence: sunxueli2015@163.com

${ }^{2}$ Department of Psychiatry, West China Hospital, Sichuan University, Chengdu

610041, China

Full list of author information is available at the end of the article
} 


\section{Background}

Bipolar disorder (BD), a type of mood disorder, generally refers to recurrent manic or hypomanic and depressive episodes that occur over a period of time. BD is a common mental illness with an early age of onset, high rates of prevalence, recurrence, morbidity and suicide, and a heavy disease burden [1]. When mild episodes are included, the incidence of $\mathrm{BD}$ in the population can reach $4.4 \%$ [2]; when atypical episodes (episodes that do not meet the diagnostic criteria of BD in the dimensions of time and severity) are also included, the incidence can reach $6.5 \%$ [3].

Biological processes that repeat approximately every $24 \mathrm{~h}$ and persist during the same period in the absence of external cues are defined as circadian rhythms [4]. The important physiological functions of the human body, including blood pressure and blood glucose, exhibit circadian fluctuations. Therefore, recent theories suggest that common diseases such as hypertension and diabetes may be caused by rhythm imbalance. In addition, BD, which is characterized by erratic changes in emotion, can also be understood as a dysrhythmia. Consequently, many studies have attempted to identify the pathogenesis of $\mathrm{BD}$ from the perspective of rhythm. For example, Westrich and Sprouse [5] found that some $\mathrm{BD}$ patients have a free-run pace of less than $24 \mathrm{~h}$ and that this shortening of the circadian period results in phase advances and usually precedes a hypomanic or manic episode. Moreover, Abreu [6] noted that BD symptoms, including mood, energy, sleep, appetite, and attention changes, all represent a change in rhythm, and some academics have suggested that mood stabilizers, the main drugs used to treat $\mathrm{BD}$, work by influencing the biological activity of the circadian clock [7].

Most recent studies have focused on the nature of BD from only a narrow point of view, namely, circadian rhythm imbalance. However, from a broad perspective, the shift in circadian rhythms might also follow the pattern common to many other diseases, developing from a normal rhythm to an abnormal rhythm and then a pathological rhythm until decompensation occurs; these latter stages correspond to the prodrome, onset and complications of clinical disease. In the simple example of diabetes, which is characterized by dysrhythmia of blood glucose, impaired glucose tolerance is the prodromal phase. In this phase, the patient's blood glucose shows abnormal rhythms that are still reversible. As the disease develops further, the patient is diagnosed with diabetes, indicating a pathological rhythm. As the disease continues to worsen, renal failure or other complications occur, and the patient enters the irreversible decompensation period. As a type of disease, BD might also follow the rules mentioned above, and the fluctuation of emotion, which is analogous in this case to blood glucose in diabetes, might follow the pattern of disease evolution. However, the current diagnostic criteria for BD list phenomenological symptoms for the onset period only and do not describe any features of the prodromal period or complications, which leads to a low rate of diagnosis, a poor response to drugs and an unsatisfactory prognosis. Hence, it is necessary to research the prodromal period of BD. Only through discovering symptoms of the prodromal period can we stop abnormal rhythms from developing into pathological rhythms that cannot be reversed. According to most of the recent studies in the literature, the prodromal symptoms of BD may include subthreshold manic symptoms, anxiety and other symptoms, and these symptoms are often atypical [8-12]. Zeschel et al. [13] performed a retrospective study of $42 \mathrm{BD}$ patients and found that they all had certain prodromal symptoms, including instability and a change in life rhythms, before the onset of their manic or depressive episode. Some scholars have even noted that the duration of prodromal symptoms in BD might be 1.8 to 7.3 years. When that period is shorter, the rate of developing $\mathrm{BD}$ is higher and the symptoms are more severe [14]. However, out of several "prodromal" symptoms, anxiety symptoms have emerged as a priority. Patients with the chief complaint of anxiety often report poor efficacy in anxiolytic treatment and ultimately develop BD. It is difficult to make a correct diagnosis based on medical history unless the patient previously presented with mania and was hospitalized [15]. Therefore, it is necessary to study prodromal symptoms manifested as anxiety, which may have a profound impact on the treatment and prognosis of $\mathrm{BD}$.

As a result, many scholars have begun to seek the relationship between $\mathrm{BD}$ and anxiety disorders. For example, the 2013 National Epidemiological Survey on Alcohol and Related Conditions (NESARC) found that in subjects with elation or irritability, generalized anxiety disorder can be a good predictor of later hypomania [16]. Another study found that subjects who did not have panic disorder before they were recruited had a higher rate of developing $\mathrm{BD}$ if they experienced a panic attack than if they did not have a panic attack [17]. Kessler et al. [18] found that anxiety disorders can predict the occurrence of $\mathrm{BD}$ even if no other variables are considered. Furthermore, Mesman et al. [19] used a prospective method to study patients with $\mathrm{BD}$ and their offspring and found an association between anxiety disorder and BD. They mentioned that anxiety disorder is likely to be the first pathological mental process in the development of BD. Similarly, Johnson et al. [20] reported that adolescents suffering from anxiety disorders are more likely to show significant clinical features of $\mathrm{BD}$ or manic symptoms in early adulthood than those without an anxiety disorder. Additionally, Faedda et al. 
[21] conducted a meta-analysis that showed that the early onsets of panic disorder, separation anxiety and generalized anxiety disorder were risk factors for the onset of typical BD within a few years. Rucklidge et al. [22] also argued that excessive anxiety and worry leading to social dysfunction showed high sensitivity and specificity for predicting the onset of $\mathrm{BD}$.

These studies attempted to ascertain the relationship between anxiety and $\mathrm{BD}$, but they failed to determine the special features of anxiety disorder that are most likely to develop into BD or to be an atypical expression of BD in terms of rhythm. They also failed to explain why and how anxiety becomes the prodromal period of BD. From the viewpoint of psychology, anxiety is a basic emotion that can be converted or transformed into any other emotion [23]. We hypothesize that when people experience stress, the common emotion of anxiety occurs, and with the continuation of stress, this emotion gradually evolves into pathological anxiety. From that moment on, the normal rhythm of emotion is disrupted, which indicates the beginning of the prodromal period of $\mathrm{BD}$, although it is still manifested as anxiety disorder and lacks the typical symptoms of BD. If the stress persists, it may result in the recession of anxiety and the emergence of the depressive symptoms of BD. In such cases, the rhythm of emotion becomes pathological, a conversion that is difficult to reverse. If the stress continues, it may result in release (namely, disinhibition), which manifests as the manic symptoms of BD. Thus, for the group of patients who do not have depressive symptoms but first present with manic symptoms, the main mechanism of disease may be excessive selfprotection caused by their personal qualities and other factors. This self-protection causes them to bypass the pain of depression and to move directly into the manic phase, which is accompanied by positive feelings about themselves. According to our hypothesis, there might be a period between anxiety and BD that we define as atypical BD. Atypical BD shows its symptoms in the form of anxiety disorders but simultaneously possesses special features of $\mathrm{BD}$ in psychological and neurobiological aspects. Because these special features can be either inherited or contracted, some patients with anxiety might stay in the stage of common anxiety disorder without developing $\mathrm{BD}$, while others might progress to $\mathrm{BD}$ after many years. The most compelling evidence is that some anxiety patients may be cured by the use of mood stabilizers instead of anxiolytics. Hence, there is an urgent need to verify the existence of atypical $\mathrm{BD}$ and discover the differences that separate it from common anxiety disorders. If atypical BD exists as defined here, we believe that $\mathrm{BD}$ will also obey the developmental rule of rhythm and that anxiety disorders may occur in the first stage of its development.
Based on the hypothesis mentioned above, we chose patients diagnosed with anxiety disorders cured by the usage of either mood stabilizers or anxiolytics and included patients diagnosed with BD as the control group. We used a combination of retrospective and prospective methods to study the psychological and neurobiological features of all the subjects in terms of personality, endocrine indices and inflammatory cytokines for the following purposes: 1 , to analyse the differences between anxiety patients cured by mood stabilizers and those cured by anxiolytics; 2 , to determine whether the patients diagnosed with anxiety disorders but cured by mood stabilizers share some similarities with BD patients, which would further substantiate the existence of atypical BD; and 3, to explore and explain how anxiety disorders become the prodromal period of $\mathrm{BD}$ from the perspective of rhythm and to try to reveal why some common anxiety disorders do not develop into BD.

\section{Methods \\ Subjects \\ Sample size and sources}

The typical BD group comprised 48 patients diagnosed with $\mathrm{BD}$. The simple anxiety group comprised 111 patients diagnosed with anxiety disorders, and the atypical $\mathrm{BD}$ group comprised 63 patients who also met the criteria for anxiety disorders but used mood stabilizers (the specific grouping rules are listed below). These patients were selected from the Mental Health Center of West China Hospital in Chengdu from May 2014 to September 2014 using the convenience sampling method.

\section{Inclusion criteria}

All the patients but those in the typical BD group needed to meet the International Classification of Diseases, Tenth Edition (ICD-10) criteria for anxiety disorders, including generalized anxiety disorder, panic disorder, obsessivecompulsive disorder (OCD), phobias, acute stress disorder, and post-traumatic stress disorder. These patients all received anxiolytic therapy during hospitalization and completed our 1.5-year follow-up study after they were discharged from West China Hospital. The first follow-up visit was conducted 3 months after the anxiolytic therapy, the second one was completed 6 months later, the third was completed 12 months later, and the last was completed 18 months later. The flow chart is shown in Fig. 1.

The simple anxiety group All the subjects in the simple anxiety group met the criteria presented in inclusion criteria, and their treatment was assessed as effective at the first follow-up based on reductions in their clinical scale scores and their scores on the Clinical Global Impression (CGI) scale (i.e., reductions in both 


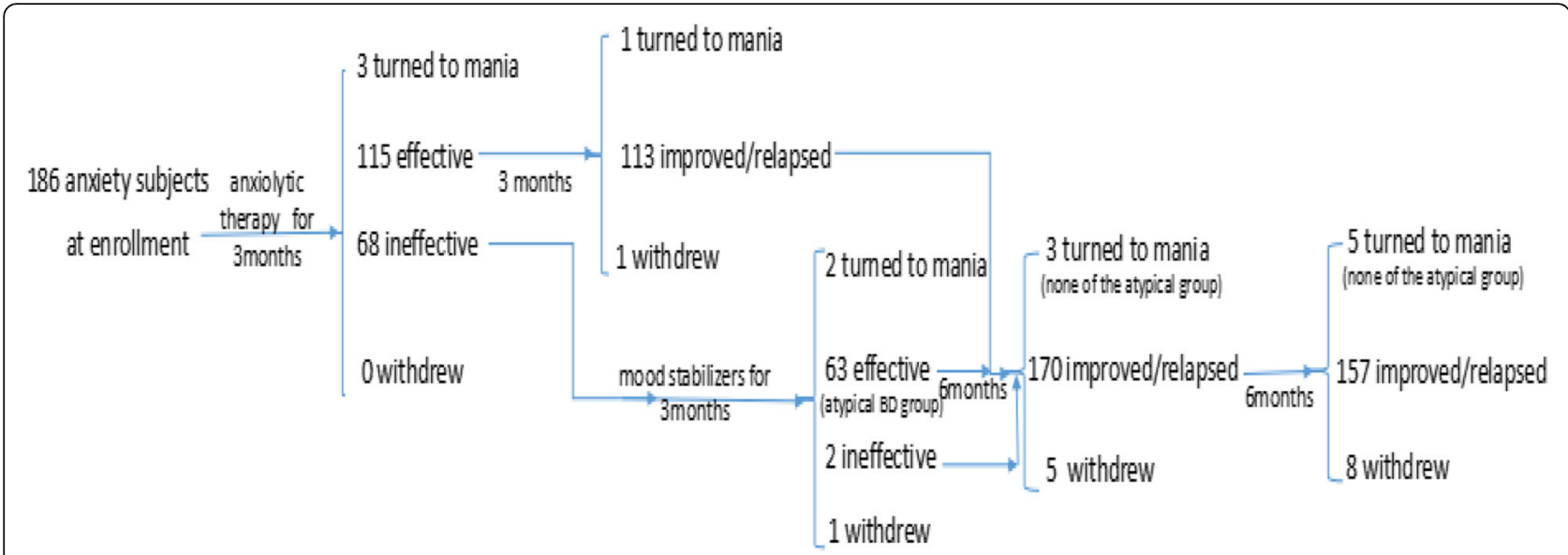

Fig. 1 The outcome of subjects and the flow chart of follow-up

the Hamilton Anxiety Scale (HAMA) and the YaleBrown Obsessive Compulsive Scale (YBOCS) $\geq 25 \%$ and an overall CGI $\leq 3$ ), but patients who showed manic symptoms at subsequent follow-up visits were excluded.

The atypical BD group All the subjects in the atypical BD group also met the criteria in inclusion criteria, and their treatment was assessed as ineffective or nonsignificant at the first follow-up based on their clinical scale and CGI scores. Furthermore, these patients were given mood stabilizers, such as valproate, lamotrigine or lithium carbonate, for treatment after anxiolytic therapy proved ineffective. The mood stabilizers were prescribed at the second follow-up visit, 3 months later. Patients who exhibited manic symptoms at subsequent follow-up visits were excluded.

The BD group All the subjects in the BD group met the ICD-10 diagnostic criteria for bipolar disorder with anxiety disorders as their first-onset disease and were currently in the onset phase of $\mathrm{BD}$ rather than in remission.

Patients who progressed to mania during the followup process Subjects who met the criteria in inclusion criteria and displayed manic symptoms during the follow-up period, as assessed by Young Mania Rating Scale (YMRS) scores and the duration of symptoms (i.e., YMRS scores $\geq 6$ points and symptoms consistent with the ICD-10 criteria for a hypomanic/manic episode), were considered new BD patients.

\section{Exclusion criteria}

Anxiety patients with any of the following features were excluded:
(1) suffering from non-anxiety mental disorders, such as $\mathrm{BD}$, depression, or schizophrenia, or from severe physical illness (within the past 3 months) that might make the patient unable to complete the questionnaires;

(2) unable to read or comprehend the questionnaires;

(3) unwilling to participate or uncooperative.

Patients with typical BD who met any of the following exclusion criteria were not enrolled:

(1)suffering from other mental disorders in addition to $\mathrm{BD}$ or from neurological diseases or severe physical illness (within the past 3 months) that might make them unable to complete the questionnaires;

(2)Unable to read or comprehend the questionnaires;

(3) unwilling to participate or uncooperative.

\section{Measures}

Survey tools

The basic demographic questionnaire The graphic questionnaire was designed by members of our research team to collect data regarding the participants' demographic features and the clinical features of their diseases. (The intact version of this questionnaire can be found in the Additional file 1, and the specific items are listed in Tables 1, 2 and 3). The item on suicidal ideation was adapted from the 10th item of the Montgomery-Asberg Depression Rating Scale and was scored on a 6-point scale. The higher the score was, the more severe the symptom.

Hamilton Anxiety scale (HAMA) [24] The HAMA includes 14 items. Each item is answered on a 5point scale. A total score lower than 6 indicates no anxiety. In addition, the scale can be divided into two factors: somatic and mental anxiety. The HAMA was used to assess all anxiety patients in our study and was 
Table 1 Demographic characteristics

\begin{tabular}{|c|c|c|c|c|c|c|c|c|c|c|c|c|}
\hline \multicolumn{2}{|c|}{ Characteristic } & \multicolumn{3}{|l|}{$\mathrm{BD}(n=48)$} & \multicolumn{3}{|c|}{ Atypical $(n=63)$} & \multicolumn{3}{|c|}{ Anxiety $(n=111)$} & \multirow[t]{2}{*}{$x^{2}$} & \multirow[t]{2}{*}{$\mathrm{F}$} \\
\hline & & Mean \pm SD & $n$ & Percentage (\%) & Mean \pm SD & $n$ & Percentage (\%) & Mean \pm SD & $n$ & Percentage (\%) & & \\
\hline \multicolumn{2}{|l|}{ Age (years) } & $33.06 \pm 14.53$ & & & $34.33 \pm 15.55$ & & & $37.38 \pm 12.15$ & & & & 0.676 \\
\hline \multirow[t]{2}{*}{ Sex } & Male & & 15 & 31.3 & & 18 & 28.6 & & 39 & 35.1 & 0.276 & \\
\hline & Female & & 33 & 68.8 & & 45 & 71.4 & & 72 & 64.9 & & \\
\hline \multirow[t]{2}{*}{ Nationality } & Han & & 45 & 93.8 & & 60 & 95.2 & & 105 & 94.6 & 0.039 & \\
\hline & Minority & & 3 & 6.3 & & 3 & 4.8 & & 6 & 5.4 & & \\
\hline \multirow[t]{4}{*}{ Birth place } & SC & & 42 & 87.5 & & 51 & 80.9 & & 105 & 94.6 & 5.728 & \\
\hline & CQ & & 3 & 6.3 & & 0 & 0 & & 0 & 0 & & \\
\hline & $\mathrm{GZ}$ & & 0 & 0 & & 3 & 4.8 & & 0 & 0 & & \\
\hline & Others & & 3 & 6.3 & & 9 & 14.3 & & 6 & 5.4 & & \\
\hline \multirow[t]{2}{*}{ Residence } & City & & 36 & 75 & & 54 & 85.7 & & 90 & 81.1 & 0.680 & \\
\hline & Village & & 12 & 25 & & 9 & 14.3 & & 21 & 18.9 & & \\
\hline \multirow[t]{5}{*}{ Education } & Primary & & 0 & 0 & & 0 & 0 & & 9 & 8.1 & 5.267 & \\
\hline & Middle & & 12 & 25 & & 15 & 23.8 & & 24 & 21.6 & & \\
\hline & High & & 24 & 50 & & 27 & 42.9 & & 33 & 29.7 & & \\
\hline & Bachelor & & 12 & 25 & & 21 & 33.3 & & 45 & 40.5 & & \\
\hline & Master & & 0 & 0 & & 0 & 0 & & 0 & 0 & & \\
\hline \multirow[t]{5}{*}{ Marriage } & Unmarried & & 27 & 56.3 & & 30 & 47.6 & & 24 & 21.6 & $14.493^{* *}$ & \\
\hline & Married & & 12 & 25 & & 27 & 42.9 & & 81 & 73 & & \\
\hline & Divorced & & 6 & 12.5 & & 6 & 9.5 & & 6 & 5.4 & & \\
\hline & Remarried & & 0 & 0 & & 0 & 0 & & 0 & 0 & & \\
\hline & Widowed & & 0 & 6.3 & & 0 & 0 & & 0 & 0 & & \\
\hline \multirow[t]{8}{*}{ Work } & None & & 24 & 50 & & 24 & 38.1 & & 30 & 27 & 3.926 & \\
\hline & Student & & 12 & 25 & & 18 & 28.6 & & 15 & 13.5 & & \\
\hline & Worker & & 6 & 12.5 & & 0 & 0 & & 12 & 10.8 & & \\
\hline & Teacher & & 3 & 6.3 & & 3 & 4.8 & & 9 & 8.1 & & \\
\hline & Doctor & & 0 & 0 & & 0 & 0 & & 3 & 2.7 & & \\
\hline & $\begin{array}{l}\text { Civil } \\
\text { servant }\end{array}$ & & 0 & 0 & & 6 & 9.5 & & 12 & 10.8 & & \\
\hline & Staff & & 0 & 0 & & 12 & 19 & & 18 & 16.2 & & \\
\hline & Others & & 3 & 6.3 & & 0 & 0 & & 12 & 10.8 & & \\
\hline
\end{tabular}

**P $<0.01$

Han represents the Han nationality, SC represents Sichuan province, CQ represents Chongqing city, and GZ represents Guizhou province

administered by experienced psychiatrists at the time of enrolment and at the first and the second follow-up visits. We defined treatment as effective when the reduction rate was $\geq 25 \%$ and as markedly effective when the reduction rate was $\geq 50 \%$.

Young Mania Rating Scale (YMRS) [24] The YMRS comprises 11 items. The 1st, 2nd, 3rd, 4th, 7th, 10 th, and 11th items are scored on a 4-point scale, while the remaining items are scored on an 8-point scale. A score of less than 6 indicates no mania. This scale was used to assess all the anxiety patients in our study and was administered by experienced psychiatrists at the time of enrolment and at the first, second, third and fourth follow-up visits.

Yale-Brown Obsessive-Compulsive Scale (YBOCS) [24] The YBOCS consists of 10 items scored on a 5point scale. The higher the score is, the more severe the patient's condition. The scale was used to assess the anxiety patients with obsessive-compulsive symptoms in our study and was administered by experienced psychiatrists at the time of enrolment and at the first and second follow-up visits. We defined treatment as effective when 
Table 2 Clinical features of disease (categorical variables)

\begin{tabular}{|c|c|c|c|c|c|c|c|c|}
\hline \multirow[t]{2}{*}{ Variables } & & \multicolumn{2}{|c|}{$\mathrm{BD}(n=48)$} & \multicolumn{2}{|c|}{ Atypical $(n=63)$} & \multicolumn{2}{|c|}{ Anxiety $(n=111)$} & \multirow[t]{2}{*}{$x^{2}$} \\
\hline & & $n$ & $\%$ & $n$ & $\%$ & $n$ & $\%$ & \\
\hline \multirow[t]{8}{*}{ Type of BD } & Hypomania & 0 & 0 & & & & & \\
\hline & Non psychotic mania & 12 & 25 & & & & & \\
\hline & Psychotic mania & 3 & 6.3 & & & & & \\
\hline & Mixed state & 15 & 31.3 & & & & & \\
\hline & Remission & 0 & 0 & & & & & \\
\hline & Mild depression & 12 & 25 & & & & & \\
\hline & Non psychotic major depression & 3 & 6.3 & & & & & \\
\hline & Psychotic major depression & 3 & 6.3 & & & & & \\
\hline \multirow[t]{4}{*}{ Type of anxiety } & GAD & & & 54 & 85.7 & 75 & 67.6 & 5.607 \\
\hline & OCD & & & 6 & 9.5 & 27 & 24.3 & \\
\hline & Stress related disorders & & & 3 & 4.8 & 0 & 0 & \\
\hline & Panic Disorder & & & 0 & 0 & 9 & 8.1 & \\
\hline \multirow[t]{2}{*}{ First onset } & No & 48 & 100 & 48 & 76.2 & 90 & 81.1 & 4.187 \\
\hline & Yes & 0 & 0 & 15 & 23.8 & 21 & 18.9 & \\
\hline \multirow[t]{4}{*}{ Type of first onset } & GAD & 36 & 75 & 57 & 90.5 & 78 & 70.3 & 2.090 \\
\hline & OCD & 6 & 12.5 & 3 & 4.8 & 24 & 21.6 & \\
\hline & Stress related disorders & 3 & 6.3 & 3 & 4.8 & 0 & 0 & \\
\hline & Panic Disorder & 3 & 6.3 & 0 & 0 & 9 & 8.1 & \\
\hline \multirow[t]{2}{*}{ Family history } & No & 42 & 87.5 & 51 & 81 & 99 & 89.2 & 0.796 \\
\hline & Yes & 6 & 12.5 & 12 & 19 & 12 & 10.8 & \\
\hline \multirow[t]{2}{*}{ Drug abuse } & No & 45 & 93.8 & 60 & 95.2 & 108 & 97.3 & 0.399 \\
\hline & Yes & 3 & 6.3 & 3 & 4.8 & 3 & 2.7 & \\
\hline \multirow[t]{2}{*}{ Other disease } & No & 45 & 93.8 & 51 & 81 & 87 & 78.4 & 1.867 \\
\hline & Yes & 3 & 6.3 & 12 & 19 & 24 & 21.6 & \\
\hline
\end{tabular}

the reduction rate was $\geq 25 \%$ and as markedly effective when the reduction rate was $\geq 50 \%$.

Clinical Global Impression scale (CGI) [24] The CGI consists of the Disease Severity and Overall Efficacy subscales, which assess the severity of the disease (7- point scale; the larger the number, the more serious the disease) and the efficacy of the treatment (7-point scale; the larger the number, the worse the efficacy), respectively. It was used to evaluate the efficacy of treatment and was administered by experienced psychiatrists at the time of enrolment and at the first and second follow-up visits.

Table 3 Clinical features of disease (continuous variables)

\begin{tabular}{|c|c|c|c|c|}
\hline \multirow[t]{2}{*}{ Variables } & $\mathrm{BD}(n=48)$ & Atypical $(n=63)$ & Anxiety $(n=111)$ & \multirow[t]{2}{*}{$\mathrm{F}$} \\
\hline & Mean \pm SD & Mean \pm SD & Mean \pm SD & \\
\hline Number of onsets & $5.50 \pm 2.53^{a}$ & $3.19 \pm 1.81$ & $3.29 \pm 1.99^{b}$ & $7.351^{* *}$ \\
\hline Age of first onset (years) & $22.50 \pm 10.69^{c}$ & $28.67 \pm 13.76$ & $30.62 \pm 12.32$ & 2.397 \\
\hline Months since diagnosis & $64.87 \pm 73.35$ & $59.14 \pm 60.24$ & $54.84 \pm 85.92$ & 0.097 \\
\hline Frequency (number/year) & $1.72 \pm 2.87$ & $1.15 \pm 1.27$ & $1.01 \pm 1.54$ & 0.820 \\
\hline Suicidal ideation & $2.00 \pm 2.07^{d}$ & $1.76 \pm 2.09^{\mathrm{e}}$ & $0.57 \pm 1.42$ & $4.996^{* *}$ \\
\hline
\end{tabular}


NEO Five-Factor Inventory (NEO-FFI) [25] The NEOFFI consists of 60 items and includes a total of five subscales, each subscale comprising 12 items scored on a 5 -point scale. The Chinese version of the inventory has been shown to have good reliability and validity [25]. The five personality features are as follows: (1) Neuroticism $(\mathrm{N})$, which refers to the tendency to experience negative emotions. The typical low score is 20.4, while the typical high score is 38.8. (2) Extraversion (E), which refers to the level of active commitment to the outside world. The typical low score is 26 , while the typical high score is 42. (3) Openness $(\mathrm{O})$, which refers to the degree of imagination and curiosity. The typical low score is 32 , while the typical high score is 47. (4) Agreeableness (A), which refers to the capacity for cooperation and maintaining harmony in society. The typical low score is 30 , while the typical high score is 48 . (5) Conscientiousness $(C)$, which refers to organization, persistence, and motivation in terms of goal-oriented behaviour. It also reflects the degree of self-control and the ability to delay meeting needs. The typical low score is 36 , while the typical high score is 44 [26].

\section{Examination of endocrine axes}

The hypothalamic-pituitary-thyroid (HPT) axis indices examined in this study included thyroid-stimulating hormone (TSH; normal level is $0.27-4.2 \mathrm{mU} / \mathrm{L}$ ), triiodothyronine (T3; normal level is $1.3-3.1 \mathrm{nmol} / \mathrm{L}$ ), thyroxine (T4; normal level is $62-164 \mathrm{nmol} / \mathrm{L}$ ), free triiodothyronine (FT3; normal level is $3.60-7.50 \mathrm{pmol} / \mathrm{L}$ ), and free thyroxine (FT4; normal level is $12.0-22.0 \mathrm{pmol} / \mathrm{L}$ ). The hypothalamic-pituitary-adrenal (HPA) axis indices of interest included plasma total cortisol (PTC, normal level is $147.3-609.3 \mathrm{nmol} / \mathrm{L}$ ) measured at 8:00 AM and adrenocorticotropic hormone $(\mathrm{ACTH}$, normal level is $5.0-78 \mathrm{ng} / \mathrm{L}$ ). Blood samples were drawn at the beginning of treatment and analysed by the laboratory of West China Hospital.

\section{Examination of inflammatory cytokines}

The inflammatory cytokines examined in this study included interleukin-6 (IL-6, normal level is $0.00-7.00 \mathrm{pg}$ / $\mathrm{mL}$ ), interleukin-8 (IL-8, normal level is $0-62 \mathrm{pg} / \mathrm{mL}$ ), interleukin-10 (IL-10, normal level is $0.0-9.1 \mathrm{pg} / \mathrm{mL}$ ), tumour necrosis factor- $\alpha$ (TNF- $\alpha$, normal level is $<8.1 \mathrm{pg} /$ $\mathrm{mL}$ ) and C-reactive protein (CRP, normal is $<5 \mathrm{mg} / \mathrm{L}$ ). Blood samples were drawn at the beginning of treatment and analysed by the laboratory of West China Hospital.

\section{Data collection}

This study used a combination of prospective and retrospective methods. In the retrospective part, we reviewed the clinical features of $\mathrm{BD}$ patients and compared them with those of the anxiety patients. In the prospective part, we tracked those anxiety patients to determine how their disease evolved. This innovative combination allowed us to discover the developmental rule of how anxiety turned to BD. Throughout the course of the study, no treatment plan was interfered with, and only the development of disease was recorded. The BD patients only needed to complete the basic demographic questionnaire, the NEO-FFI and a blood draw at the time of enrolment. All the subjects signed informed consent documents. The research was approved by the Institutional Review Board of West China Hospital. The study included 234 subjects, of whom 48 belonged to the BD group. At the time of enrolment, there were 186 anxiety patients; at the end of follow-up, there were 111 remaining patients who met the criteria for the simple anxiety group, 63 who met the criteria for the atypical $\mathrm{BD}$ group, and 14 who progressed to mania during the study. The withdrawal rates for the 3-month, 6-month, 12-month, and 18-month follow-up periods were 0 , $1.1 \%, 2.9 \%$, and $4.8 \%$, respectively. (For the specific stages of grouping and the number of people lost to follow-up, see Fig. 1).

\section{Statistical analysis}

Descriptive statistics were computed for all variables. Differences between categorical variables were analysed with $X^{2}$ tests or a rank-sum test. The independent samples $\mathrm{t}$-test was used to compare the HAMA, YMRS, and YBOCS scores of the atypical BD group and the simple anxiety group. ANOVA was used to analyse the differences among the three groups (i.e., the BD group, the atypical BD group, and the simple anxiety group) in NEO-FFI scores, endocrine indices, and inflammatory cytokines. Then, pairwise comparison was used to explore the differences between two groups at a time. (If the variance was homogeneous, Bonferroni correction was selected; if the variance was heterogeneous, Tamhane's T2 was selected).

All statistical analyses were carried out using the Statistical Package for the Social Sciences (version 21.0). Statistical significance was set at $P<0.05$.

\section{Results \\ Basic conditions among the BD, atypical BD and simple anxiety groups \\ Demographic characteristics}

The subjects' demographic data are summarized in Table 1 . The three groups were not significantly different $(P>0.05)$ in age, sex composition, nationality, place of birth, residence, education or work. Marital status among the three groups was significantly different $\left(X^{2}=14.493\right.$, 
$P<0.01)$. Married was the most common marital status in the simple anxiety group, while unmarried was the most common status in the other groups.

\section{Clinical features of disease among the three groups}

Tables 2 and 3 show the clinical features of all participants. There was no significant difference $(P>0.05)$ between the atypical $\mathrm{BD}$ group and the simple anxiety group regarding the distribution of the type of anxiety. The clinical features were not significantly different among the three groups $(P>0.05)$ in whether the patients were at their first onset, the type of first onset, family history, history of drug abuse, history of other diseases, age of first onset, years since diagnosis or frequency of onset. The number of previous episodes and the suicidal ideation score were significantly different $(F=7.351,4.996$; $P<0.01)$ among the three groups.

The pairwise comparison results showed that the number of onsets in the BD group was significantly higher than those of the remaining two groups $(P<0.01)$; the age of first onset of the BD group was significantly younger than that of the simple anxiety group $(P<0.05)$; and the suicidal ideation score in the simple anxiety group was significantly lower than those in the other two groups $(P<0.05)$. (See Table 3 and notes).

\section{Characteristics of symptoms between the atypical BD group} and the simple anxiety group at enrolment

The differences in symptoms between the two groups are shown in Table 4. Due to the large number of items, only those with significant differences are listed here. The subjects in the atypical $\mathrm{BD}$ group received higher scores than those in the simple anxiety group on the items of sleep, irritability, disordered thought form and content, aggressive behaviour, and appearance. Their cognitive impairment and depression were more serious and their sensory symptoms, autonomic nervous system symptoms and anxiety level on performance were less serious than those of the simple anxiety group. The level of somatic anxiety of the simple anxiety group was more prominent than that of the atypical BD group. In addition, the subjects with obsessive-compulsive symptoms in the atypical BD group had more serious obsessive-compulsive symptoms than the corresponding ones from the simple anxiety group.

\section{Comparing efficacy of treatment between the atypical BD and simple anxiety groups}

The HAMA and YBOCS in the different follow-up periods are shown in Table 5. No significant difference $(t=1.247 ; P>0.05)$ in total HAMA score was found between the two groups at enrolment, but a difference did exist in total YBOCS score $(t=2.052 ; P<0.05)$; specifically, the atypical BD group scored significantly higher than the simple anxiety group. There were significant differences between the two groups in total HAMA and YBOCS scores of at the first follow-up $(t=2.328,3.214$; $P<0.05)$. The total HAMA and YBOCS scores of the atypical BD group at the second follow-up had no significant difference compared with the corresponding scores

Table 4 YMRS, HAMA and YBOCS scores of the atypical and anxiety groups

\begin{tabular}{|c|c|c|c|}
\hline Variables & $\begin{array}{l}\text { Atypical }(n 1=63, n 2=6) \\
\text { Mean } \pm \text { SD }\end{array}$ & $\begin{array}{l}\text { Anxiety }(n 1=111, n 2=27) \\
\text { Mean } \pm S D\end{array}$ & $\mathrm{t}$ \\
\hline YMRS-4 (sleep) & $0.67 \pm 0.90$ & $0.03 \pm 0.16$ & $4.569^{* * *}$ \\
\hline YMRS-5 (irritability) & $0.86 \pm 0.95$ & $0.14 \pm 0.48$ & $4.698^{* * *}$ \\
\hline YMRS-7 (thought form) & $0.05 \pm 0.22$ & 0 & $2.340^{*}$ \\
\hline YMRS-8 (thought content) & $0.14 \pm 0.35$ & 0 & $4.214^{* * *}$ \\
\hline YMRS-9 (aggressive behaviour) & $0.05 \pm 0.22$ & 0 & $2.340^{*}$ \\
\hline YMRS-10 (appearance) & $0.05 \pm 0.22$ & 0 & $2.340^{*}$ \\
\hline Total score of YMRS & $1.81 \pm 1.94$ & $0.16 \pm 0.49$ & $5.433^{* * *}$ \\
\hline HAMA-5 (cognitive function) & $1.90 \pm 0.53$ & $1.54 \pm 0.83$ & $2.646^{* *}$ \\
\hline HAMA-6 (depressed mood) & $2.05 \pm 1.06$ & $1.46 \pm 0.86$ & $3.534^{* *}$ \\
\hline HAMA-8 (sensory symptoms) & $0.67 \pm 1.00$ & $1.35 \pm 1.24$ & $-3.200^{* *}$ \\
\hline HAMA-13 (ANS symptoms) & $1.14 \pm 0.65$ & $1.46 \pm 0.89$ & $-2.099^{*}$ \\
\hline HAMA-14 (performance) & $1.57 \pm 0.67$ & $1.97 \pm 0.49$ & $-3.546^{* *}$ \\
\hline Somatic anxiety factor & $4.14 \pm 3.82$ & $5.76 \pm 3.46$ & $-2.503^{*}$ \\
\hline Total score of YBOCS & $22.50 \pm 4.95$ & $19.22 \pm 2.95$ & $2.052^{*}$ \\
\hline
\end{tabular}

${ }^{*} P<0.05,{ }^{* *} P<0.01,{ }^{* * *} P<0.001$

ANS represents the autonomic nervous system, $n 1$ represents the number of subjects who completed the YMRS and the HAMA, $n 2$ represents the number of subjects who completed the YBOCS 
Table 5 The reduction rates of HAMA and YBOCS scores in the atypical and anxiety groups

\begin{tabular}{|c|c|c|c|c|c|c|c|c|c|}
\hline \multirow[t]{2}{*}{ Variables } & \multicolumn{3}{|c|}{ Anxiety $(n 1=111, n 2=27)$} & \multicolumn{5}{|c|}{ Atypical $(n 1=63, n 2=6)$} & \multirow[t]{2}{*}{$x^{2}$} \\
\hline & Enrolment & $\begin{array}{l}3 \text { months } \\
\text { later }\end{array}$ & Reduction rate $^{a}$ & Enrolment & $\begin{array}{l}3 \text { months } \\
\text { later }\end{array}$ & $\begin{array}{l}6 \text { months } \\
\text { later }\end{array}$ & Reduction rate $^{b}$ & Reduction rate $^{c}$ & \\
\hline Total HAMA score & $16.92 \pm 3.26$ & $5.58 \pm 1.46^{* *}$ & 67.02 & $16.13 \pm 3.98$ & $14.82 \pm 3.15$ & $5.34 \pm 1.21$ & 8.12 & 66.90 & 0.659 \\
\hline Total YBOCS score & $19.22 \pm 2.95$ & $8.36 \pm 2.69^{* *}$ & 56.50 & $22.50 \pm 4.95$ & $20.69 \pm 4.35$ & $9.58 \pm 2.87$ & 8.04 & 57.42 & 0.852 \\
\hline
\end{tabular}

**P $<0.01$

$n 1$ represents the number of subjects who completed the HAMA, $n 2$ represents the number of subjects who completed the YBOCS, ${ }^{a}$ represents the reduction rate between enrolment and 3 months later in the anxiety group; ${ }^{b}$ represents the reduction rate between enrolment and 3 months later in the atypical group; ${ }^{c}$ represents the reduction rate between enrolment and 6 months later in the atypical group; the value of $x^{2}$ represents the comparison between reduction rate a and reduction rate $c$

of the simple anxiety group at the first follow-up $(t=-0.912,1.385 ; P>0.05)$. This means that at the second follow-up, the severity of symptoms of the atypical $\mathrm{BD}$ group was similar to that of the simple anxiety group. The final reduction rates of HAMA and YBOCS scores between the two groups were not significantly different $\left(x^{2}=0.659,0.852 ; P>0.05\right)$. Thus, it was evident that all the symptoms of the subjects in both groups were improved after appropriate treatment. In other words, the treatment was effective.

The CGI results over different follow-up periods are shown in Table 6 . The distributions of the disease severity and overall efficacy of the simple anxiety group were significantly different between the time of enrolment and the time of first follow-up $(\mathrm{Z}=2.583,3.689 ; P<0.01)$. The distribution of the disease severity and overall efficacy of the atypical BD group were not significantly different between the time of enrolment and the time of first follow-up $(\mathrm{Z}=0.674,0.968 ; P>0.05)$, while there was a significant difference between the time of enrolment and the time of the second follow-up $(\mathrm{Z}=2.435,2.874 ; \mathrm{P}<0.01)$. Thus, it could be proved that all the symptoms of the subjects from both groups were improved after appropriate treatment. In other words, the treatment was effective.

Table 6 The changes in CGI score in the atypical group and the anxiety group

\begin{tabular}{|c|c|c|c|c|c|c|c|c|}
\hline \multirow[t]{2}{*}{ Variables } & \multicolumn{3}{|c|}{ Anxiety $(n=111)$} & \multicolumn{5}{|c|}{ Atypical $(n=63)$} \\
\hline & $\begin{array}{l}\text { Enrolment } \\
n(\%)\end{array}$ & $\begin{array}{l}3 \text { months later } \\
n(\%)\end{array}$ & $Z_{1}$ & $\begin{array}{l}\text { Enrolment } \\
n(\%)\end{array}$ & $\begin{array}{l}3 \text { months later } \\
n(\%)\end{array}$ & $\begin{array}{l}6 \text { months later } \\
n(\%)\end{array}$ & $z_{2}$ & $z_{3}$ \\
\hline Disease severity & & & $2.583^{* *}$ & & & & 0.674 & $2.435^{* *}$ \\
\hline No assessment & 0 & 0 & & 0 & 0 & 0 & & \\
\hline Normal & 0 & $5(4.5)$ & & 0 & 0 & $4(6.3)$ & & \\
\hline Borderline & 0 & $35(31.5)$ & & 0 & 0 & $23(36.5)$ & & \\
\hline Mild & $10(9.0)$ & $55(49.5)$ & & $9(14.3)$ & $12(19.0)$ & $27(42.9)$ & & \\
\hline Moderate & $36(32.4)$ & $16(14.5)$ & & $22(34.9)$ & $25(39.7)$ & $9(14.3)$ & & \\
\hline Obvious & $45(40.5)$ & 0 & & $24(38.1)$ & $19(30.2)$ & 0 & & \\
\hline Severe & $12(10.8)$ & 0 & & $7(11.1)$ & $6(9.5)$ & 0 & & \\
\hline Most severe & $8(7.3)$ & 0 & & $1(1.6)$ & $1(1.6)$ & 0 & & \\
\hline Overall efficacy & & & $3.689^{* * *}$ & & & & & \\
\hline No assessment & 111 & 0 & & 63 & 0 & 0 & 0.968 & $2.874^{* *}$ \\
\hline Obviously improved & 0 & $64(57.7)$ & & 0 & 0 & $41(65.1)$ & & \\
\hline Improved & 0 & $39(35.1)$ & & 0 & 0 & $16(25.4)$ & & \\
\hline Slightly improved & 0 & $8(7.2)$ & & 0 & 0 & $6(9.5)$ & & \\
\hline No change & 0 & 0 & & 0 & $61(96.8)$ & 0 & & \\
\hline Slightly deteriorated & 0 & 0 & & 0 & $2(3.2)$ & 0 & & \\
\hline Deteriorative & 0 & 0 & & 0 & 0 & 0 & & \\
\hline Obviously deteriorated & 0 & 0 & & 0 & 0 & 0 & & \\
\hline
\end{tabular}


Differences in big five personality traits among the $B D$, atypical BD and simple anxiety groups

Differences in big five personality traits among the three groups

The extraversion, openness, agreeableness and conscientiousness scores were all significantly different among the three groups $(F=6.863,5.545,17.593,11.472 ; P<0.05)$, while no significant difference was found on the neuroticism score $(P>0.05)$.

\section{Pairwise comparisons among the three groups}

The pairwise comparison results showed the following: on the dimension of extraversion, the simple anxiety group had higher scores than the atypical BD group or the BD group, and the difference was statistically significant $(P<0.05)$; on the dimension of openness, the simple anxiety group had lower scores than the atypical BD group or the $\mathrm{BD}$ group, and the difference was statistically significant $(P<0.05)$; on the dimension of agreeableness, the simple anxiety group had higher scores than the atypical BD group or the $\mathrm{BD}$ group, and the difference was statistically significant $(P<0.05)$; and on the dimension of conscientiousness, the simple anxiety group had higher scores than the atypical $\mathrm{BD}$ group or the $\mathrm{BD}$ group, and the difference was statistically significant $(P<0.05)$ (see Table 7 and notes).

\section{Differences in endocrine indices among the BD, atypical $\mathrm{BD}$ and simple anxiety groups \\ Abnormality rates of endocrine indices among the three groups}

The abnormality rates of the three groups are shown in Table 8 . There was no significant difference $(P>0.05)$ in the abnormality rate of any index of the HPT axis or the HPA axis between the BD group and the atypical BD group. The abnormality rates of TSH, FT3, FT4 and $\mathrm{ACTH}$ in both the $\mathrm{BD}$ group and the atypical BD group were all significantly higher than those in the simple anxiety group $(P<0.01)$.
Differences in endocrine indices among the three groups The endocrine indices of the three groups are shown in Table 9. All seven indices of the HPT axis and HPA axis among the three groups were significantly different $(F=11.321,7.638,4.995,6.820,4.937,5.808,13.325$; $P<0.05)$.

\section{Pairwise comparison among the three groups}

The pairwise comparison results showed the following: the level of TSH was higher in the atypical BD group than in the BD group or the simple anxiety group, and the difference was statistically significant $(P<0.05)$; the level of T3 was lower in the simple anxiety group than in the atypical $\mathrm{BD}$ group or the $\mathrm{BD}$ group, and the difference was statistically significant $(P<0.05)$; the level of FT3 was lower in the BD group than in the atypical BD group or the simple anxiety group, and the difference was statistically significant $(P<0.05)$; the level of T4 was lower in the simple anxiety group than in the atypical BD group or the BD group, and the difference was statistically significant $(P<0.05)$; the level of FT4 was lower in the simple anxiety group than in the atypical BD group or the $\mathrm{BD}$ group, and the difference was statistically significant $(P<0.05)$; the level of ACTH was lower in the $\mathrm{BD}$ group than in the atypical BD group or the simple anxiety group, and the difference was statistically significant $(P<0.05)$; and the level of PTC was lower in the BD group than in the atypical BD group or the simple anxiety group, and the difference was statistically significant $(P<0.05)$ (see Table 9 and notes).

\section{Differences in inflammatory cytokines among the BD, atypical BD and simple anxiety groups \\ Abnormality rates of inflammatory cytokines among the three groups}

The abnormality rates of the three groups are shown in Table 10. There were no significant differences $(P>0.05)$ in the abnormality rates of inflammatory cytokines between the $\mathrm{BD}$ group and the atypical $\mathrm{BD}$ group. The abnormality rates of IL-6, IL-8, TNF- $\alpha$ and CRP in both

Table 7 Differences in Big Five personality traits among the BD, atypical BD and simple anxiety groups

\begin{tabular}{|c|c|c|c|c|c|}
\hline Variables & $\begin{array}{l}\text { Typical points } \\
\text { low/high }\end{array}$ & $\begin{array}{l}\mathrm{BD}(n=48) \\
\text { Mean } \pm \text { SD }\end{array}$ & $\begin{array}{l}\text { Atypical }(n=63) \\
\text { Mean } \pm \text { SD }\end{array}$ & $\begin{array}{l}\text { Anxiety }(n=111) \\
\text { Mean } \pm \text { SD }\end{array}$ & $\mathrm{F}$ \\
\hline Neuroticism & $20.4 / 38.8$ & $43.63 \pm 6.50$ & $43.81 \pm 5.74$ & $42.59 \pm 6.78$ & 0.291 \\
\hline Extraversion & $26 / 42$ & $31.81 \pm 6.36$ & $32.95 \pm 4.79^{\mathrm{a}}$ & $36.81 \pm 4.74^{b}$ & $6.863^{* *}$ \\
\hline Openness & $32 / 47$ & $42.31 \pm 6.22$ & $41.24 \pm 6.13^{c}$ & $37.41 \pm 5.06^{d}$ & $5.545^{* *}$ \\
\hline Agreeableness & $30 / 48$ & $34.44 \pm 2.89$ & $33.76 \pm 3.83^{e}$ & $39.51 \pm 4.41^{f}$ & $17.593^{* * *}$ \\
\hline Conscientiousness & $36 / 44$ & $34.38 \pm 4.05$ & $35.67 \pm 3.73^{9}$ & $39.32 \pm 3.87^{h}$ & $11.472^{* * *}$ \\
\hline
\end{tabular}

**P $<0.01, * * * P<0.001$

${ }^{\mathrm{a}}$ The anxiety group was significantly higher than the atypical group $(P=0.000) .{ }^{\mathrm{b}}$ The anxiety group was significantly higher than the $\mathrm{BD}$ group $(P=0.000) .{ }^{\mathrm{c}}$ The anxiety group was significantly lower than the atypical group $(P=0.000)$. ${ }^{\mathrm{d}}$ The anxiety group was significantly lower than the BD group $(P=0.003)$. ${ }^{\mathrm{T}}$ The anxiety group was significantly higher than the atypical group $(P=0.000) .{ }^{f}$ The anxiety group was significantly higher than the $\mathrm{BD}$ group $(P=0.000) .{ }^{9}$ The anxiety group was significantly higher than the atypical group $(P=0.000)$. ${ }^{\mathrm{h}}$ The anxiety group was significantly higher than the $\mathrm{BD}$ group $(P=0.000)$ 
Table 8 Abnormality rates of endocrine indices among the BD, atypical BD and simple anxiety groups

\begin{tabular}{|c|c|c|c|c|c|c|c|}
\hline \multirow[t]{2}{*}{ Variables } & & \multirow{2}{*}{$\begin{array}{l}\mathrm{BD}(n=48) \\
n(\%)\end{array}$} & \multirow{2}{*}{$\begin{array}{l}\text { Atypical }(n=63) \\
n(\%)\end{array}$} & \multirow{2}{*}{$\begin{array}{l}\text { Anxiety }(n=111) \\
n(\%)\end{array}$} & \multirow[t]{2}{*}{$x^{2 a}$} & \multirow[t]{2}{*}{$x^{2 b}$} & \multirow[t]{2}{*}{$x^{2 c}$} \\
\hline & & & & & & & \\
\hline \multirow[t]{5}{*}{$\overline{\mathrm{HPT}}$} & TSH & $12(25.0)$ & 18 (28.6) & $3(2.7)$ & 0.074 & $9.412^{* *}$ & $20.227^{* * *}$ \\
\hline & $\mathrm{T} 3$ & $0(0)$ & $0(0)$ & $0(0)$ & - & - & - \\
\hline & FT3 & $3(6.3)$ & $5(7.9)$ & $0(0)$ & 2.671 & $6.993^{* *}$ & $7.012^{* *}$ \\
\hline & $\mathrm{T} 4$ & $0(0)$ & $0(0)$ & $0(0)$ & - & - & - \\
\hline & FT4 & $3(6.3)$ & $5(7.9)$ & $0(0)$ & 0.158 & $6.993^{* *}$ & $7.012^{* *}$ \\
\hline \multirow[t]{2}{*}{ HPA } & ACTH & $6(12.5)$ & $6(9.5)$ & $0(0)$ & 0.111 & $7.186^{* *}$ & $7.132^{* *}$ \\
\hline & PTC & $6(12.5)$ & $21(33.3)$ & $30(27.0)$ & 2.517 & 1.566 & 0.591 \\
\hline
\end{tabular}

**P $P<0.01,{ }^{* * *} P<0.001$

${ }^{a}$ represents the comparison between the BD group and the atypical group; ${ }^{b}$ represents the comparison between the BD group and the anxiety group; ${ }^{c}$ represents the comparison between the atypical group and the anxiety group

the BD group and the atypical BD group were all significantly higher than those in the simple anxiety group $(P<0.05)$.

\section{Differences in inflammatory cytokine levels among the three groups}

The inflammatory cytokine levels of the three groups are shown in Table 11. There were significant differences in the levels of IL-6, IL-10, TNF- $\alpha$ and CRP among the three groups $(F=9.022,12.193,8.632,8.708 ; P<0.001)$.

\section{Pairwise comparisons among the three groups}

The pairwise comparison results showed the following: the level of IL- 6 was higher in the atypical BD group than in the $\mathrm{BD}$ group or the simple anxiety group, and the difference was statistically significant $(P<0.05)$; the level of IL-10 was lower in the atypical $\mathrm{BD}$ group than in the BD group or the simple anxiety group, and the difference was statistically significant $(P<0.05)$; the level of TNF- $\alpha$ was higher in the atypical $\mathrm{BD}$ group than in the $\mathrm{BD}$ group or the simple anxiety group, and the difference was statistically significant $(P<0.05)$; and the level of CRP was significantly higher in the atypical BD group than in the $\mathrm{BD}$ group or the simple anxiety group, and the difference was statistically significant $(P<0.05)$ (see Table 11 and notes).

\section{The rate of progression to mania}

Through the entire follow-up, a total of 14 people developed mania (the number of patients developing mania in different periods is listed in Fig. 1), representing $7.53 \%$ of the number of subjects in the prospective study. Their demographic data were not significantly different from those of the remaining anxiety patients $(P>0.05)$.

\section{Discussion}

This is the first study to explore the links and differences between anxiety disorders and BD from the perspective of rhythm to determine which type of anxiety disorder may be associated with the atypical

Table 9 Differences in endocrine indices among the BD, atypical BD and simple anxiety groups

\begin{tabular}{|c|c|c|c|c|c|}
\hline \multicolumn{2}{|c|}{ Variables } & \multirow{2}{*}{$\begin{array}{l}\mathrm{BD}(n=48) \\
\text { Mean } \pm \text { SD } \\
2.80 \pm 1.62\end{array}$} & \multirow{2}{*}{$\begin{array}{l}\text { Atypical }(n=63) \\
\text { Mean } \pm \text { SD } \\
4.44 \pm 2.87^{\mathrm{a}}\end{array}$} & \multirow{2}{*}{$\begin{array}{l}\text { Anxiety }(n=111) \\
\text { Mean } \pm \text { SD } \\
2.14 \pm 0.73^{b}\end{array}$} & \multirow{2}{*}{$\begin{array}{l}F \\
11.321^{* * *}\end{array}$} \\
\hline$\overline{\mathrm{HPT}}$ & $\mathrm{TSH}$ & & & & \\
\hline & T3 & $2.24 \pm 0.42^{c}$ & $2.36 \pm 0.36$ & $1.98 \pm 0.36^{d}$ & $7.638^{* *}$ \\
\hline & $\mathrm{FT} 3$ & $4.45 \pm 0.51$ & $4.98 \pm 0.69^{e}$ & $4.94 \pm 0.49^{f}$ & $4.995^{* *}$ \\
\hline & $\mathrm{T} 4$ & $91.22 \pm 19.59$ & $92.92 \pm 18.43^{9}$ & $79.25 \pm 10.12^{h}$ & $6.820^{* *}$ \\
\hline & $\mathrm{FT} 4$ & $17.26 \pm 3.30$ & $17.07 \pm 2.89^{\circ}$ & $15.32 \pm 1.82^{j}$ & $4.937^{*}$ \\
\hline \multirow[t]{2}{*}{ HPA } & ACTH & $21.96 \pm 11.06$ & $37.06 \pm 27.58^{k}$ & $41.80 \pm 16.64^{\prime}$ & $5.808^{* *}$ \\
\hline & PTC & $341.68 \pm 151.71$ & $544.82 \pm 152.71^{\mathrm{m}}$ & $540.25 \pm 121.16^{n}$ & $13.325^{* * *}$ \\
\hline
\end{tabular}

\footnotetext{
${ }^{*} P<0.05,{ }^{* *} P<0.01,{ }^{* * *} P<0.001$
}

${ }^{\mathrm{a}}$ The atypical group was significantly higher than the BD group $(P=0.002) .{ }^{\mathrm{b}}$ The atypical group was significantly higher than the anxiety group $(P=0.000)$

${ }^{\mathrm{C}}$ The BD group was significantly higher than the anxiety group $(P=0.026)$. ${ }^{\mathrm{d}}$ The atypical group was significantly higher than the anxiety group $(P=0.000)$

${ }^{\mathrm{e}}$ The atypical group was significantly higher than the BD group $(P=0.004) .{ }^{\mathrm{f}}$ The anxiety group was significantly higher than the $\mathrm{BD}$ group $(P=0.004)$

${ }^{9}$ The atypical group was significantly higher than the anxiety group $(P=0.000)$. ${ }^{\text {h }}$ The BD group was significantly higher than the anxiety group $(P=0.003)$

'The atypical group was significantly higher than the anxiety group $(P=0.000)$. ${ }^{\text {j}}$ The BD group was significantly higher than the anxiety group $(P=0.005)$

${ }^{\mathrm{k}}$ The atypical group was significantly higher than the BD group $(P=0.026)$. 'The anxiety group was significantly higher than the $\mathrm{BD}$ group $(P=0.001)$

${ }^{\mathrm{m}}$ The atypical group was significantly higher than the BD group $(P=0.000) .{ }^{\mathrm{n}}$ The anxiety group was significantly higher than the BD group $(P=0.000)$ 
Table 10 Abnormality rates of inflammatory cytokines among the BD, atypical BD and simple anxiety groups

\begin{tabular}{|c|c|c|c|c|c|c|}
\hline Variables & $\begin{array}{l}\mathrm{BD}(n=48) \\
n(\%)\end{array}$ & $\begin{array}{l}\text { Atypical }(n=63) \\
n(\%)\end{array}$ & $\begin{array}{l}\text { Anxiety }(n=111) \\
n(\%)\end{array}$ & $x^{2 a}$ & $x^{2 b}$ & $x^{2 c}$ \\
\hline IL-6 & $9(18.8)$ & $9(14.3)$ & $3(2.7)$ & 0.176 & $4.832^{*}$ & $7.384^{* *}$ \\
\hline IL-8 & $4(8.3)$ & $6(9.5)$ & $0(0)$ & 0.016 & $7.074^{* *}$ & $7.132^{* *}$ \\
\hline IL-10 & $0(0)$ & $0(0)$ & $0(0)$ & - & - & - \\
\hline TNF & $21(43.8)$ & $30(47.6)$ & $15(13.5)$ & 0.070 & $8.927^{* *}$ & $18.203^{* * *}$ \\
\hline CRP & $3(6.3)$ & $3(4.8)$ & $0(0)$ & 0.052 & $6.993^{* *}$ & $5.356^{*}$ \\
\hline
\end{tabular}

${ }^{*} P<0.05,{ }^{* *} P<0.01,{ }^{* * *} P<0.001$

${ }^{a}$ represents the comparison between the BD group and the atypical group; ${ }^{b}$ represents the comparison between the BD group and the anxiety group; ${ }^{c}$ represents the comparison between the atypical group and the anxiety group

form of $\mathrm{BD}$ and to compare this anxiety disorder with common anxiety disorders to identify their neurobiological and psychological differences. These investigations were an attempt to show the existence of a prodromal period of $\mathrm{BD}$, as well as to provide some basis for the argument that $\mathrm{BD}$ may also abide by the law of disease development and that the essence of BD may be the dysrhythmia of anxious mood.

\section{The clinical features of the three groups}

The results of the present study show that the number of onsets in typical BD patients was significantly higher than those in the other groups, and their age at onset was significantly lower than that of the patients in the simple anxiety group but not significantly different from that of the patients in the atypical BD group. Furthermore, their suicidal ideation scores did not differ significantly from those of the atypical BD group but were significantly higher than those of the simple anxiety group, that is, the patients in the simple anxiety group had a relatively low suicidal ideation score. These findings suggest that the features of the atypical BD group were similar to those of the BD group but different from those of the simple anxiety group. The trend of the data shows that from the simple anxiety group to the atypical $\mathrm{BD}$ group and then the $\mathrm{BD}$ group, the age of onset decreased, while the frequency of onset gradually increased. The suicidal ideation score also showed a gradual increasing trend. It was possible to infer that the patients in the atypical BD group were in a transition period of $\mathrm{BD}$, characterized by a shift from an abnormal rhythm to a pathological rhythm. With anxiety beginning first, some patients sharing the characteristics of BD (such as severe suicidal ideation or young age of onset) may have continued to deteriorate when not treated with mood stabilizers. These patients may have been at the stage of abnormal rhythm at this time, namely, the stage of atypical BD - the prodromal period of $\mathrm{BD}$. Because their rhythm had not yet become pathological, their symptoms were atypical and difficult to recognize. In addition, according to previous reports, suicide is the leading cause of death in mood disorder patients [1], and every 10 patients with $B D$ attempt suicide before their first manic episode [27]. Therefore, the existence and severity of suicidal ideation may be the turning point for distinguishing whether anxiety disorders are indicative of $\mathrm{BD}$.

The YMRS, HAMA and YBOCS results at enrolment showed that the patients in the atypical BD group had more prominent symptoms related to sleep, irritability, the form and content of thought disorder, aggressive behaviour and appearance compared with the patients in the simple anxiety group. Furthermore, their cognitive dysfunction (mainly in terms of inattention and poor memory) and depressed mood were more serious, while their sensory symptoms, autonomic neurological

Table 11 Differences in inflammatory cytokine levels among the BD, atypical BD and simple anxiety groups

\begin{tabular}{lllll}
\hline Variables & BD $(n=48)$ & Atypical $(n=63)$ & Anxiety $(n=111)$ & Mean \pm SD \\
& Mean \pm SD & Mean \pm SD & $2.53 \pm 2.72^{\text {b }}$ & $9.022^{* * *}$ \\
\hline IL-6 & $3.52 \pm 3.54$ & $6.42 \pm 4.19^{\mathrm{a}}$ & $24.76 \pm 78.82$ & 0.025 \\
IL-8 & $27.92 \pm 55.31$ & $22.86 \pm 40.00$ & $4.43 \pm 0.86^{\mathrm{d}}$ & $12.193^{* * *}$ \\
IL-10 & $4.66 \pm 0.55$ & $3.49 \pm 0.86^{c}$ & $5.67 \pm 2.08^{f}$ & $8.632^{* * *}$ \\
TNF & $7.69 \pm 3.13$ & $10.89 \pm 7.76^{\mathrm{e}}$ & $2.62 \pm 2.85^{\mathrm{h}}$ & $8.708^{* * *}$ \\
CRP & $2.84 \pm 3.38$ & $4.44 \pm 3.83^{\mathrm{g}}$ & \\
\hline
\end{tabular}

***P $<0.001$

${ }^{\mathrm{a}}$ The atypical group was significantly higher than the BD group $(P=0.007) .{ }^{\mathrm{b}}$ The atypical group was significantly higher than the anxiety group $(P=0.000)$.

${ }^{\mathrm{c}}$ The atypical group was significantly lower than the BD group $(P=0.000)$. ${ }^{\mathrm{d}}$ The atypical group was significantly lower than the anxiety group $(P=0.000)$. ${ }^{\mathrm{T}}$ The atypical group was significantly higher than the BD group $(P=0.035) .{ }^{\mathrm{f}}$ The atypical group was significantly higher than the anxiety group $(P=0.000) .{ }^{9}$ The atypical group was significantly higher than the BD group $(P=0.042) .{ }^{\mathrm{h}}$ The atypical group was significantly higher than the anxiety group $(P=0.000)$ 
symptoms and anxious behaviour when talking were less serious. However, the somatic anxiety of the patients in the simple anxiety group was more prominent. These results demonstrate that the clinical features of disease in the atypical BD group and the simple anxiety group differ somewhat. Studies have shown that before typical $\mathrm{BD}$ symptoms appear, the patient will present with a series of atypical symptoms and disruptive changes in biorhythms, such as decreased sleep requirements, an inability to concentrate, irritability, decreased energy, fatigue, and anhedonia [13]. Therefore, in our study, the symptoms of the atypical BD group that differed from those of the patients in the simple anxiety group may confirm the presence of prodromal symptoms of BD. Recent epidemiological and clinical studies show a strong correlation between OCD and mood disorders [28]. Some scholars have even suggested that the subset of OCD characterized by an episodic course may itself represent an atypical form of BD rather than a simple comorbidity [29]. Therefore, this study's finding that the YBOCS score of the atypical BD group was significantly higher than that of the simple anxiety group could further support the existence of atypical BD.

Big five personality trait differences among the three groups The results of this study indicate that there was no significant difference in any factor of the NEO-FFI between the typical BD group and the atypical BD group, while all factors of these two groups differed significantly from those of the simple anxiety group. This finding shows that the assessment of personality characteristics can distinguish BD from normal anxiety disorders. This link to personality may be an inherent reason why some patients with anxiety disorders stay at the abnormal rhythm stage rather than progress to a pathological rhythm, namely, BD.

The results of the NEO-FFI indicate that the three groups did not differ significantly in the neuroticism factor, which illustrates that the patients in the three groups were more inclined to experience negative emotions and often had a poor ability to regulate their emotions. Chen et al. [30] also found that patients with anxiety disorders had obvious neurotic personality tendencies. Barnett et al. [31] reported that compared with the general population, BD patients also tended to present a high degree of nervousness, as measured with the NEO-FFI. The simple anxiety group's score on the extraversion factor was significantly higher than that of the remaining two groups, suggesting that patients with $\mathrm{BD}$ are often quieter and less interested in the outside world than patients with simple anxiety. This finding is consistent with the results of Barnett et al. [31]. On the openness factor, the scores of the typical BD group and the atypical BD group were significantly higher than those of the simple anxiety group, which shows that patients with $\mathrm{BD}$ are often imaginative and creative. One possible reason is that $\mathrm{BD}$ patients have a more open attitude and more easily accept new things, especially during manic episodes [32]. Nowakowska et al. [33] used the NEO-FFI to assess $\mathrm{BD}$ patients and found that they scored higher than the control group on the openness factor. Galvez et al. [34] also discovered that $\mathrm{BD}$ patients have a considerable degree of creativity, realism and compliance. Conversely, patients with anxiety disorders tend to be pragmatic, traditional and conservative, which can be confirmed by their highly sensitive, cautious and alert personalities. On the agreeableness factor, the scores of the typical BD group and the atypical BD group were significantly lower than those of the simple anxiety group, indicating that patients with $\mathrm{BD}$ are generally reluctant to care for others and that they present certain problems in terms of social cooperation and harmony. Gruber et al. [35] also revealed that patients with BD tend to show less compassion. On the conscientiousness factor, the scores of the typical and atypical BD groups were significantly lower than those of the simple anxiety group, indicating that the behaviour of patients with BD is not standardized and that they are careless and have low work efficiency; these findings are reflected by the clinical characteristics of BD patients. This result is also consistent with those of Barnett et al. [31] and Nowakowska et al. [33]. Overall, anxiety patients with the personality traits of poor stability, poor agreeableness, and low conscientiousness may actually be presenting with the prodromal stage of $\mathrm{BD}$.

\section{Differences in endocrine indicators among the three groups}

The results of our study suggest that the differences in the abnormality rates of the HPT and HPA axis indicators between the typical BD group and the atypical BD group were not significant and that these values were all significantly higher in the typical and atypical BD groups than in the simple anxiety group. This lack of separation between typical and atypical BD demonstrates that the patients in the atypical BD group are essentially similar to those of the $\mathrm{BD}$ group from an endocrinological perspective. Although most patients with BD have no apparent thyroid disease, subtle changes in thyroid function are often found during examinations [36], and related studies indicate that HPT axis dysfunction may represent a potential phenotype of BD [37]. The HPA axis is the body's main neuroendocrine system for coping with stress and adjusting emotions and mood [38]. It is clear that impairment in the function of the HPA axis is closely correlated with mood disorders [39], which explains why the BD patients and atypical BD patients in our study had higher abnormality rates of HPA axis values. RemlingerMolenda et al. [40] also speculated that HPA axis dysfunction may be a characteristic of $\mathrm{BD}$ patients. 
The results of the pairwise comparison showed that in terms of TSH, the atypical BD group had significantly higher values than the other two groups, which may explain why some patients in the prodromal stage of BD do not exhibit typical characteristics of BD. Those patients might have their own specific characteristics that could cause their anxiety to develop closer to BD. Regarding T3, the simple anxiety group had significantly lower values than the other two groups. This difference may be due to the activation of their HPA axis, which may suppress the relatively inactive thyroid hormone in the peripheral tissue from transforming into T3, which prompts the body to store more energy in response to stress [41]. This result further confirmed that anxiety might be the basic emotion involved in the development of BD. Regarding FT3, the typical BD group had significantly lower values than the other two groups. Mendonca et al. [42] also found that patients with BD had decreased FT3 and that the degree of decrease had a negative correlation with the severity of the disease. This result tells us only that atypical BD usually shares some features with common anxiety disorders, making them difficult to recognize. Regarding T4, both the typical and atypical BD groups had significantly higher values than the simple anxiety group. It has been suggested that increased T4 after hospitalization is positively correlated with the severity of BD and that its rate of decline is associated with a better prognosis [43]. These correlations show that $\mathrm{T} 4$ can stand alone as an endocrine indicator that distinguishes between $\mathrm{BD}$ and anxiety disorders. Similarly, regarding FT4, both the typical and atypical BD groups had significantly higher values than the simple anxiety group. Southwick et al. [44] also observed temporarily increased FT4 in hospitalized BD patients during both manic and depressive episodes. Regarding ACTH and PTC, the typical BD group had significantly lower values than the other two groups, indicating that although the typical and atypical BD groups had the same trend towards HPA axis impairment, the patients in the atypical group retained some characteristics in common with anxiety disorders. Furthermore, many studies have found that both generalized anxiety disorder and obsessive-compulsive disorder patients had increased levels of ACTH and PTC [45-47], making it difficult to distinguish atypical BD from anxiety disorders based on these factors.

\section{Differences in the inflammatory cytokine index among the three groups}

The results of our study suggest that the rates of abnormality for the inflammatory cytokines did not differ significantly between the typical BD group and the atypical BD group. Furthermore, the rates of abnormal IL-6, IL-8, TNF- $\alpha$ and CRP in those two groups were all significantly higher than those of the simple anxiety group, providing additional confirmation that atypical BD does exist. There are some data showing that increased immune and inflammatory signals may be closely related to the pathological aetiology of mood disorders and, therefore, may become new therapeutic targets for the development of more-effective treatments [48].

The pairwise comparison results show that the IL-6, TNF- $\alpha$ and CRP values of the atypical BD group were significantly higher than those of the other two groups, while the IL-10 value was significantly lower than those of the other two groups. It is well known that IL-6 and TNF- $\alpha$ are pro-inflammatory cytokines, while IL-10 is an anti-inflammatory cytokine. Our results suggest that patients in the atypical BD group may have more-serious inflammatory and immune responses and that their prominent changes in inflammatory cytokines could be another major feature distinguishing them from patients with ordinary anxiety disorders. In recent years, an increasing number of studies have found an imbalance in pro-inflammatory and anti-inflammatory cytokines in BD patients. For instance, the level of TNF- $\alpha$ in BD patients increased during both depressive and manic episodes [49]. Kauer-Sant'Anna et al. [50] also reported that the levels of TNF- $\alpha$ and IL- 6 increased in BD patients during their early episodes. Other studies have confirmed that pro-inflammatory cytokines, such as IL-6 and TNF$\alpha$, can stimulate the hepatic biosynthesis system to produce CRP [51]. As a result, the level of CRP in our atypical BD group increased, as did the levels of TNF- $\alpha$ and IL-6. However, we were surprised that we failed to find significant differences between the typical BD group and the simple anxiety group in terms of inflammatory cytokine indicators. A possible reason for this result is that the first onset of the patients enrolled in the typical $\mathrm{BD}$ group was anxiety disorders in all cases and that they had been diagnosed with BD. Therefore, they could not avoid the use of mood stabilizers for treatment, and related research has confirmed that mood stabilizers can lower the conventional starting components of the immune inflammatory signalling pathways [48]. It is easy to understand why the characteristics of the typical BD patients differed from those of the atypical BD patients but were similar to those of the anxiety patients.

\section{The rate of progression to mania}

The rate of progression to mania illustrates that throughout the process, some of the anxiety patients appeared to manifest manic symptoms quickly, which further demonstrates that a transition from anxiety to $\mathrm{BD}$ does exist. However, we removed them from the last analysis because these patients might possess their own features different from those of atypical $\mathrm{BD}$, allowing them to transform quickly. In other 
words, a patient with atypical BD may never develop typical BD and may only sustain the atypical symptoms as a variation of $\mathrm{BD}$, or they may eventually develop BD over a long period of time. This proposition needs to be tested in further research.

\section{Conclusions}

As a result of our analyses and comparisons, we conclude that the progression from anxiety disorders to bipolar disorder may represent a continuous disease process, with some specific anxiety disorders (namely, atypical BD) representing the phase of abnormal rhythm within the $\mathrm{BD}$ disease spectrum. Only patients who presented inherent characteristics similar to those of $\mathrm{BD}$, that is, those in the prodromal period, can continue to develop a pathological rhythm and ultimately present with $\mathrm{BD}$. However, these special $\mathrm{BD}$ patients also have some unique features that could represent the turning points at which anxiety disorders develop into BD; these features include severe suicidal ideation, changes from HPA axis to HPT axis activation, and elevated inflammatory cytokines. Finally, our study presents a methodology that can be used to explore other psychiatric diseases that also might have prodrome, onset and complication periods from the perspective of biorhythms.

\section{Additional file}

Additional file 1: Demographic data and relevant scales. (DOCX $22 \mathrm{~kb}$ )

\begin{abstract}
Abbreviations
ACTH: Adrenocorticotropic Hormone; AD: Anxiety disorder; BD: Bipolar disorder; CGI: Clinical Global Impression; CRP: C- Reactive Protein; FT3: Free Triiodothyronine; FT4: Free Thyroxine; HAMA: Hamilton Anxiety Scale; HPA axis: Hypothalamic - Pituitary - Adrenal axis; HPT axis: Hypothalamic - Pituitary Thyroid axis; ICD-10: International Classification of Diseases, Tenth Edition; IL-10: Interleukin-10; IL-6: Interleukin-6; IL-8: Interleukin-8; NEO-FFI: NEO Fivefactor Inventory; NESARC: National Epidemiological Survey on Alcohol and related diseases condition; NIMH: National Institute of Mental Health; OCD: Obsessive-compulsive disorder; PTC: Cortisol; T3: Triiodothyronine; T4: Thyroxine; TNF-a: Tumor Necrosis Factor -a; TSH: Thyroid Stimulating Hormone; YBOCS: Yale - Brown Obsessive Compulsive Scale; YMRS: Young Mania Rating Scale
\end{abstract}

\section{Acknowledgements}

Not applicable

\section{Funding}

Not applicable

\section{Availability of data and materials}

The datasets used and/or analyzed during the current study available from the corresponding author on reasonable request.

\section{Authors' contributions}

All authors read and approved the final manuscript. The first author, ND, collected the data with other authors except for the corresponding author, and she also wrote the original manuscript. YLZ and JG were responsible for the statistical analysis and data input. XZ checked the whole manuscript for grammar. The corresponding author XLS designed the research and was responsible for the contact.
Ethics approval and consent to participate

All subjects signed informed consent. The research was approved by the Institutional Review Board of West China Hospital.

Consent for publication

Not applicable

\section{Competing interests}

The authors declare that they have no competing interests

\section{Publisher's Note}

Springer Nature remains neutral with regard to jurisdictional claims in published maps and institutional affiliations.

\section{Author details}

${ }^{1}$ Department of Psychiatry, The Fourth People's Hospital of Chengdu, Chengdu 610031, China. 'Department of Psychiatry, West China Hospital, Sichuan University, Chengdu 610041, China.

Received: 13 November 2016 Accepted: 12 October 2017

Published online: 24 October 2017

References

1. Jiang KD, Huang JZ. Bipolar disorder. Beijing: People's Medical Publishing House; 2012.

2. Hirschfeld RM, Calabrese JR, Weissman MM, et al. Screening for bipolar disorder in the community. J Clin Psychiatry. 2003;64:53-9.

3. Angst J. Epidemiology of the bipolar spectrum. L'Encéphale. 1995;21(6):37-42.

4. Czeisler CA, Gooley JJ. Sleep and circadian rhythms in humans. Cold Spring Harb Symp Quant Biol. 2007;72:579-97.

5. Westrich L, Sprouse J. Circadian rhythm dysregulation in bipolar disorder. Curr Opin Investig Drugs. 2010;11(7):779-87.

6. Abreu T, Braganca M. The bipolarity of light and dark: a review on bipolar disorder and circadian cycles. J Affect Disord. 2015;185:219-29.

7. Hallam KT, Olver JS, Horgan JE, McGrath C, Norman TR. Low doses of lithium carbonate reduce melaton in light sensitivity in healthy volunteers. Int J Neuropsychopharmacol. 2005;8(2):255-9.

8. Leopold K, Ritter P, Correll CU, et al. Risk constellations prior to the development of bipolar disorders: rationale of a new risk assessment tool. J Affect Disord. 2012;136(3):1000-10.

9. Bechdolf A, Ratheesh A, Wood SJ, et al. Rationale and first results of developing at-risk (prodromal) criteria for bipolar disorder. Curr Pharm Des. 2012;18(4):358-75.

10. Geoffroy PA, Leboyer M, Scott J. Predicting bipolar disorder: what can we learn from prospective cohort studies? L'Encéphale. 2015;41(1):10-6.

11. Correll CU, Hauser M, Penzner JB, et al. Type and duration of subsyndromal symptoms in youth with bipolar I disorder prior to their first manic episode. Bipolar Disord. 2014;16(5):478-92.

12. Malhi GS, Bargh DM, Coulston CM, Das P, Berk M. Predicting bipolar disorder on the basis of phenomenology: implications for prevention and early intervention. Bipolar Disord. 2014;16(5):455-70.

13. Zeschel E, Correll CU, Haussleiter IS, et al. The bipolar disorder prodrome revisited: is there a symptomatic pattern? J Affect Disord. 2013;151:551-60.

14. Skjelstad DV, Malt UF, Holte A. Symptoms and signs of the initial prodrome of bipolar disorder: a systematic review. J Affect Disord. 2010;126(1-2):1-13.

15. Katzow JJ, Hsu DJ, Nassir GS. The bipolar spectrum: a clinical perspective. Bipolar Disord. 2003;5(6):436-42.

16. Homish GG, Marshall D, Dubovsky S, Leonard KE. Predictors of later bipolar disorder in patients with subthreshold symptoms. J Affect Disord. 2013;144:129-33.

17. Kinley DJ, Walker JR, Enns MW, Sareen J. Panic attacks as a risk for later psychopathology: results from a nationally representative survey. Depress Anxiety. 2011;28:412-9.

18. Kessler RC, Rubinow DR, Holmes C, Abelson JM, Zhao SY. The epidemiology of DSM-III-R bipolar I disorder in a general population survey. Psychol Med. 1997;27:1079-89.

19. Mesman E, Nolen WA, Reichart CG, Wals M, Hillegers MHJ. The Dutch bipolar offspring study: 12-year follow-up. Am J Psychiatry. 2013;170:542-9. 
20. Johnson JG, Cohen P, Brook JS. Associations between bipolar disorder and other psychiatric disorders during adolescence and early adulthood: a community-based longitudinal investigation. Am J Psychiatry. 2000;157:1679-81.

21. Faedda GL, Serra G, Marangoni C, et al. Clinical risk factors for bipolar disorders: a systematic review of prospective studies. J Affect Disord. 2014;168:314-21.

22. Rucklidge JJ. Retrospective parent report of psychiatric histories: do checklists reveal specific prodromal indicators for postpubertal-onset pediatric bipolar disorder? Bipolar Disord. 2008;10:56-66.

23. Vodušek W, Parnas J, Tomori M, Skodlar B. The phenomenology of emotion experience in first-episode psychosis. Psychopathology. 2014;47:252-60.

24. Sun XL. Psychiatry. 3rd ed. Beijing: Higher Education Press; 2008.

25. Yao RS, Liang LY. Analysis of the application of simplified NEO-FFI to undergraduates. Chin. J Clin Psychol. 2010;18(4):457-9.

26. Lawrence A, Pervin, Oliver P, John, Huang XT. Handbook of personality: theory and research. (the $1^{\text {st }}$ version). Shanghai: East China Normal University Press; 2003.

27. Howes OD, Falkenberg I. Early detection and intervention in bipolar affective disorder: targeting the development of the disorder. Curr Psychiatry Rep. 2011;13(6):493-504.

28. Kessler RC, McGonagle KA, Zhao S, et al. Lifetime and 12-month prevalence of DSM-III-R psychiatric disorders in the United States: results from the National Comorbidity Survey. Arch Gen Psychiatry. 1994;51:8-19.

29. Swartz CM, Shen WWI. Episodic obsessive compulsive disorder bipolar? A report of four cases. J Affect Disord. 1999;56:61-6.

30. Chen XY, Yang DS. The psychological and physiological characteristic of GAD. Chin. J Nerv Ment Dis. 1993;19(2):66-9.

31. Barnett JH, Huang J, Perlis RH, et al. Personality and bipolar disorder: dissecting state and trait associations between mood and personality. Psychol Med. 2011:41:1593-604.

32. Chiaroni P, Hantouche EG, Gouvernet J, Azorin JM, Akiskal HS. The cyclothymic temperament in healthy controls and familially at risk individuals for mood disorder: endophenotype for genetic studies? J Affect Disord. 2005;85(1):135-45.

33. Nowakowska C, Strong CM, Santosa CM, Wang PW, Ketter TA. Temperamental commonalities and differences in euthymic mood disorder patients, creative controls, and healthy controls. J Affect Disord. 2005:85:207-15.

34. Galvez JF, Thommi S, Ghaemi SN. Positive aspects of mental illness: a review in bipolar disorder. J Affect Disord. 2011;128:185-90.

35. Gruber J, Culver JL, Johnson SL, Nam JY, Keller KL, Ketter TA. Do positive emotions predict symptomatic change in bipolar disorder? Bipolar Disord. 2009;11(3):330-6.

36. Bunevicius R, Prange AJ. Thyroid disease and mental disorders: cause and effect or only comorbidity? Curr Opin Psychiatry. 2010;23:363-8.

37. Vonk R, Schot van der AC, Kahn RS, Nolen WA, Drexhage HA. Is autoimmune thyroiditis part of the genetic vulnerability (or an Endophenotype) for bipolar disorder? Biol Psychiatry. 2007;62(2):135-40.

38. Kellendonk C, Gass P, Kretz O, Schutz G, Tronche F. Corticosteroid receptors in the brain: gene targeting studies. Brain Res Bull. 2002;57:73-83.

39. Femenía T, Gómez-Galán M, Lindskog M, Magara S. Dysfunctional hippocampal activity affects emotion and cognition in mood disorders. Brain Res. 2012;1476:58-70

40. Remlinger-Molenda A, Rybakowski J. Neuroimmunology of bipolar affective disorder. Psychiatr Pol. 2010;44(1):27-38.

41. Benker G, Raida M, Olbricht T, Wagner RL, Reinhardt W, Reinwein D. TSH secretion in Cushing's syndrome: relation to glucocoricoid excess, diabetes, goitre, and the "the sick euthyroid syndrome". Clin Endocrinol. 1990;33:776-86.

42. Mendonca CA, Vandel S, Bonin B, Bertschy G, Bizouard P. Thyroid function in depressed patients. L'Encéphale. 1996;22(2):85-94.

43. Lee $S$, Chow CC, Wing YK, et al. Thyroid function and psychiatric morbidity in patients with manic disorder receiving lithium therapy. J Clin Psychopharmacol. 2000;20(2):204-9.

44. Southwick S, Mason JW, Giller EL, Kosten TR. Serum thyroxine change and clinical recovery in psychiatric inpatients. Biol Psychiatry. 1989;25(1):67-74.

45. Mantella RC, Butters MA, Amico JA, et al. Salivary cortisol is associated with diagnosis and severity of late-life generalized anxiety disorder. Psychoneuroendocrinology. 2008;33(6):773-81.
46. Lord C, Hall G, Soares CN, Steiner M. Physiological stress response in postpartum women with obsessive-compulsive disorder: a pilot study. Psychoneuroendocrinology. 2011;36(1):133-8.

47. Morgado P, Freitas D, Bessa JM, Sousa N, Cerqueira JJ. Perceived stress in obsessive-compulsive disorder is related with obsessive but not compulsive symptoms. Front Psychiatry. 2013;4(21):1-6.

48. Robert KM, Francis EL. Elevated immune-inflammatory signaling in mood disorders: a new therapeutic target? Expert Rev Neurother. 2012;12(9):1143-61.

49. Kimel M, Cifaldi M, Chen N, Revicki DA. Adalimumab plus methotrexate improved SF-36 scores and reduced the effect of rheumatoid arthritis (RA) on work activity for patients with early RA. J Rheumatol. 2008;35:206-15.

50. Kauer-Sant'Anna M, Kapczinski F, Andreazza AC, et al. Brain derived neurotrophic factor and inflammatory markers in patients with early-vs. late stage bipolar disorder. Int J Neuropsychopharmacol. 2009;12(4):447-58.

51. Li SP, Goldman ND. Regulation of human C-reactive protein gene expression by two synergistic IL-6 responsive elements. Biochemistry. 1996;35(28):9060-8.

\section{Submit your next manuscript to BioMed Central and we will help you at every step:}

- We accept pre-submission inquiries

- Our selector tool helps you to find the most relevant journal

- We provide round the clock customer support

- Convenient online submission

- Thorough peer review

- Inclusion in PubMed and all major indexing services

- Maximum visibility for your research

Submit your manuscript at www.biomedcentral.com/submit
Biomed Central 